\title{
Acute toxicity and Dose fixation studies on Chloroxylon swietenia Dc bark extracts on streptozotocin induced diabetic rats
}

\author{
B. Jayaprasad ${ }^{1 *}$, P.S. Sharavanan ${ }^{1}$, R. Sivaraj ${ }^{2}$ \\ 1,*'Department of Botany Annamalai University Annamalai nagar Tamil nadu India \\ ${ }^{2}$ R.Sivaraj Department of Pharmacology Annamalai University Annamalai nagar Tamil nadu India \\ E-mail address:*jaya.prasad46@yahoo.in, drpssharavanan@yahoo.co.in, drrsivaraj@gmail.com
}

\section{Keywords: Dose fixation, Acute toxicity, Antidiabetic, Chloroxylon swietenia}

\begin{abstract}
Diabetes mellitus (DM) is a chronic metabolic disease with the highest rates of prevalence and mortality worldwide. Chloroxylon swietenia has been used extensively in folkloric medicine. The present study aims to determine the acute toxicity of Chloroxylon swietenia bark methanol (CSBMEt) and aqueous extracts (CSBAEt) $(100,150,250,500$ and $1000 \mathrm{mg} / \mathrm{kg}$ body weight) and dose fixation of CSBMEt and CSBAEt in streptozotocin induced diabetic rats. Diabetes was induced in male albino wistar rats by single intraperitoneal injection of streptozotocin $(50 \mathrm{mg} / \mathrm{kg}$ b.w). The diabetic rats were administered with Chloroxylon swietenia bark extracts (CSBMEt and CSBAEt) $(75,125$ and $250 \mathrm{mg} / \mathrm{kg} \mathrm{b.w})$ orally by intragastric intubation for 15 days. Acute toxicity studies revealed the non-toxic nature of the CSBMEt and CSBAEt. No lethality or toxic reactions found at any doses until the end of study, whereas 75 and $125 \mathrm{mg} / \mathrm{kg} \mathrm{b} . \mathrm{w}$. doses of CSBMEt and CSBAEt produce no significant changes in the diabetic rats and $250 \mathrm{mg} / \mathrm{kg} \mathrm{b} . \mathrm{w}$. of CSBMEt and CSBAEt have significant change in the blood glucose. The results conclude that, there was no toxicity observed up to $1000 \mathrm{mg} / \mathrm{kg}$ b.w. of both the extracts and $250 \mathrm{mg} / \mathrm{kg} \mathrm{b}$.w. of CSBMEt and CSBAEt can be used as effective dose to treat diabetes.
\end{abstract}

\section{INTRODUCTION}

Diabetes mellitus (DM) is the most common endocrine disorder resulting from insulin deficiency which in turn leads to chronic hyperglycemia with disturbances of carbohydrate, fat, and protein metabolism [1]. It is a global disease, prevailing throughout the world, although its prevalence differs across countries [2], India, China, and US being the top-three when it comes to the number of hyperglycaemic patients they host [3]. Diabetic patients however cannot control their postprandial blood glucose efficiently due to the insufficient insulin secretion or response, which results in postprandial hyperglycemia and it, is an important contributing factor for diabetic complications [4]. Insulin is the dominant hormone which influencing the regulation of glucose metabolism. One of the major effects of insulin is to enhance overall glucose disposal by stimulation of glucose uptake into the target tissues [5]. Type 1 diabetes, the cause is an absolute deficiency of insulin secretion. In the other, much more prevalent category, type 2 diabetes, the cause is a combination of resistance to insulin action and an inadequate compensatory insulinsecretory response [6]. Streptozotocin has been used as a diabetogenic agent in experimental animals. Streptozotocin selectively causes damage of insulin producing pancreatic $\beta$-cells of rats. It usually related to chronically elevated blood glucose level [7].

Nevertheless, natural supplements are widely used around the world to treat diabetes, but medical research does not support their effectiveness. In these studies the low methodological quality, small sample size of tested patients, and limited number of trials deserve caution in the interpretation of the positive data and require further examination in high-quality trials [8]. Nowadays, clinical treatment of diabetes targets both insulin deficiency and resistance and more recently the prevention of pancreatic $\beta$-cell function decline [9].

An impressive number of modern drugs derived from plants, many of this isolate were based on the uses of the agents in traditional medicine [10]. Chloroxylon swietenia belongs to family of 
Rutaceae. It is a medium sized deciduous tree with a height of $900-1500 \mathrm{~cm}$ and $100-1200 \mathrm{~cm}$ girth with a spreading crown and clear bole up to $300 \mathrm{~cm}$. It is commonly called like East Indian Satinwood in English, Bhirra in Hindi, Billudu in Telugu and Vaaimaram and purasu in Tamil [11]. It is widely used in the various treatments like antioxidant, antimicrobial, mosquito larvicidal, insecticidal, anthelmintic, analgesic, anti-inflammatory, hepatoprotective etc [12]. To the best of our knowledge antidiabetic activity of Chloroxylon swietenia bark extracts on streptozotocin induced diabetic rats was not studied so far. Keeping this in view the present study was carried out to determine the acute toxicity study of Chloroxylon swietenia bark extracts and to determine the effective dosage on streptozotocin induced diabetic rats.

\section{MATERIALS AND METHOD}

\section{Chemicals and Drugs}

Streptozotocin was obtained from Sigma- Aldrich Company (Bangalore).

\section{Plant material collection, processing, and preparation of extracts}

Chloroxylon swietenia bark was collected during December from Kalvarayan Hills Kallakurichi, Tamil Nadu, India and the taxonomic identification was made by Dr. V. Chelladhurai (Research Officer-Botany Central Council for Research in Ayurvedha and Siddha, Govt. of India). Collected bark was shade dried for 2-3 weeks. Then it was grinded in an electronic blender and packed in airtight zip lock covers. Three hundred grams of powdered plant material was packed in a Soxhlet apparatus and extraction was carried out using methanol $(1 \mathrm{~L})$ for $72 \mathrm{~h}$. The solvent was evaporated $\left(45^{\circ} \mathrm{C}\right)$ under vacuum in a rotary evaporator (Heidolph, Germany). The pulverized powdered bark $(300 \mathrm{~g})$ of the plant was macerated with $1 \mathrm{~L}$ of distilled water at room temperature for 3 days with occasional shaking and filtered by cotton plug followed by Whatman filter paper (no.1) and dried at room temperature. The dried extracts were stored at $4^{\circ} \mathrm{C}$ until further assay.

\section{Experimental Animals}

Healthy adult Wistar male albino rats with body weight around $(185 \pm 5) \mathrm{g}$ at 8 to 10 weeks from birth were procured from Rajah Muthiah Medical College and Hospital (RMMCH) Annamalai University, Tamil Nadu, India. They were housed at poly propylene cages and maintained under standard conditions [12 h light and $12 \mathrm{~h}$ dark cycle, $\left.(25 \pm 3)^{\circ} \mathrm{C}\right]$. The rats were fed with standard rat pellet diet (Pranav Agro Industry Ltd, Maharastra) and given water ad libitum and maintained at Central Animal House, RMMCH. All studies were conducted in accordance with the National Institute of Health's Guide for the Care and Use of Laboratory Animals and the study was approved by the Institutional Animal Ethical Committee of Rajah Muthiah Medical College and Hospital (Proposal No. 998, Reg.No.160/1999/CPCSEA), Annamalai University, Tamil Nadu, India. Animals were acclimated for 7 days in the research facility before initiation of the experiments.

\section{Acute toxicity studies}

Healthy adult male albino wistar rats, starved overnight were divided into five groups $(\mathrm{n}=3)$ and were orally fed with methanol and aqueous extract of Chloroxylon swietenia bark in increasing dose levels of 100, 150, 250, 500 and $1000 \mathrm{mg} / \mathrm{kg}$ body weight [13]. The rats were observed continuously for $2 \mathrm{~h}$ for behavioral, neurological and autonomic profiles and after 24 and $72 \mathrm{~h}$ for any lethality [14].

\section{Experimental induction of diabetes}

Diabetes was induced by single intraperitoneal injection of freshly prepared streptozotocin (STZ) $(50 \mathrm{mg} / \mathrm{kg} \mathrm{b.w})$ in $0.1 \mathrm{M}$ citrate buffer $(\mathrm{pH}=4.5)$ to overnight-fasted rats [15]. Diabetic rats were allowed to drink $20 \%$ glucose solution overnight to overcome the initial drug-induced hypoglycemic mortality. The fasting blood glucose level was determined after 7 days, those fasting glucose levels $>250 \mathrm{mg} / \mathrm{dL}$ were considered as diabetic and taken for the study. Control rats were injected with $0.2 \mathrm{ml}$ of vehicle $(0.1 \mathrm{M}$ citrate buffer, $\mathrm{pH} 4.5)$ alone. 


\section{Experimental design}

In this experiment totally 24 rats ( 3 normal and 21 STZ diabetic surviving rats) were used. These rats were divided into eight groups of 3 rats each. The extract (CSBMEt and CSBAEt) and glibenclamide was dissolved in 2\% solution of CMC (Carboxyl methyl cellulose) in distilled water [16] or $0.5 \mathrm{ml}$ of $0.9 \%$ of saline and administered orally for 15 days.

Group I. Control rats (received $0.5 \mathrm{ml}$ of $0.9 \%$ saline orally for 15 days)

Group II. Diabetic control Group

Group III. Diabetic rats received Chloroxylon swietenia bark Aqueous extract (CSBAEt) (75mg/kg b.w dissolved in $0.5 \mathrm{ml}$ of $0.9 \%$ saline) orally for 15 days

Group IV. Diabetic rats received Chloroxylon swietenia bark Aqueous extract (CSBAEt) $(125 \mathrm{mg} / \mathrm{kg}$ b.w dissolved in $0.5 \mathrm{ml}$ of $0.9 \%$ saline) orally for 15 days

Group V. Diabetic rats received Chloroxylon swietenia bark Aqueous extract (CSBAEt) (250mg/kg b.w dissolved in $0.5 \mathrm{ml}$ of $0.9 \%$ saline) orally for 15 days

Group VI. Diabetic rats received Chloroxylon swietenia bark Methanol extract (CSBMEt) $(75 \mathrm{mg} / \mathrm{kg}$ b.w dissolved in $0.5 \mathrm{ml}$ of CMC) for 15 days

Group VII. Diabetic rats received Chloroxylon swietenia bark Methanol extract (CSBMEt) $(125 \mathrm{mg} / \mathrm{kg}$ b.w dissolved in $0.5 \mathrm{ml}$ of CMC) for 15 days

Group VIII. Diabetic rats received Chloroxylon swietenia bark Methanol extract (CSBMEt) $(250 \mathrm{mg} / \mathrm{kg}$ b.w dissolved in $0.5 \mathrm{ml}$ of CMC) for 15 days

At the end of the study period (15days), blood was collected from the tail of rats. The glucose level was determined by one touch strip (Life scan Scotland ltd UK).

\section{RESULT}

CSBMEt and CSBAEt were administered orally by increasing dose levels of 100, 150, 250, 500 and $1000 \mathrm{mg} / \mathrm{kg}$ body weight of the animals. The animals were observed individually at least once during the first $30 \mathrm{~min}$ after dosing, periodically during the first $24 \mathrm{~h}$ up to 3 days. No animals died. This result confirms that the lethal doses of both the extracts are above $1000 \mathrm{mg} / \mathrm{kg}$. Hence, $75 \mathrm{mg} / \mathrm{kg}, 125 \mathrm{mg} / \mathrm{kg}$ and $250 \mathrm{mg} / \mathrm{kg}$ of the extract were chosen for the dose fixation study. The dose fixation studies of the CSBAEt (Fig - 1) and CSBMEt (Fig - 2) results suggest that, blood glucose level was found to be increased in STZ induced diabetic control rats. 75 and $125 \mathrm{mg} / \mathrm{kg} \mathrm{b.w}$. doses of CSBMEt and CSBAEt produce no significant changes and $250 \mathrm{mg} / \mathrm{kg} \mathrm{b.w.} \mathrm{of} \mathrm{CSBMEt} \mathrm{and}$ CSBAEt have significant change in the blood glucose level of diabetic rats.

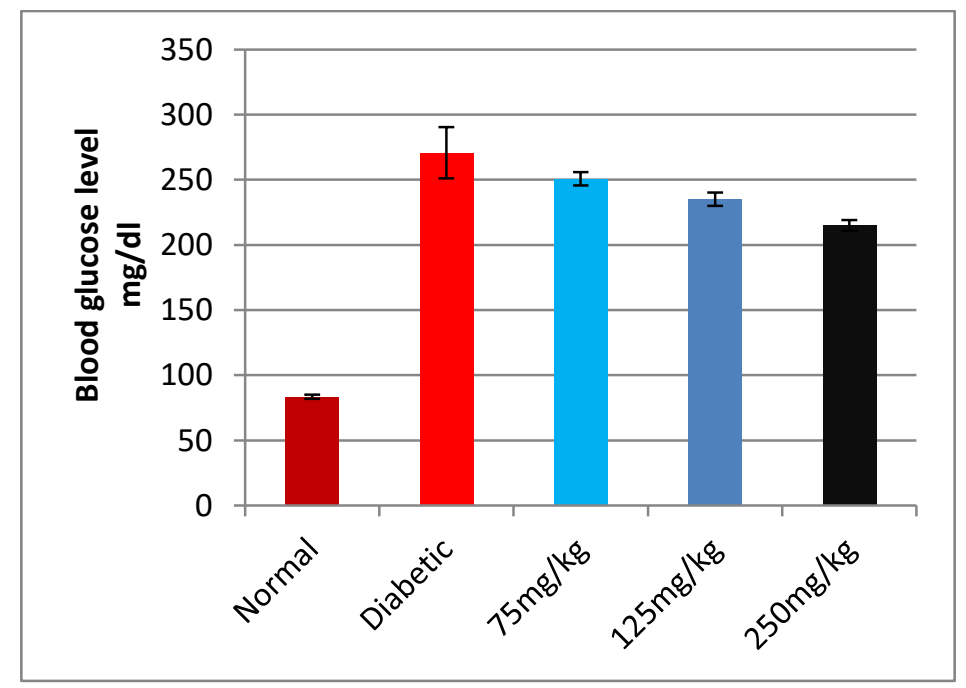

Fig - 1 Effect of CSBAEt on STZ induced diabetic rats 


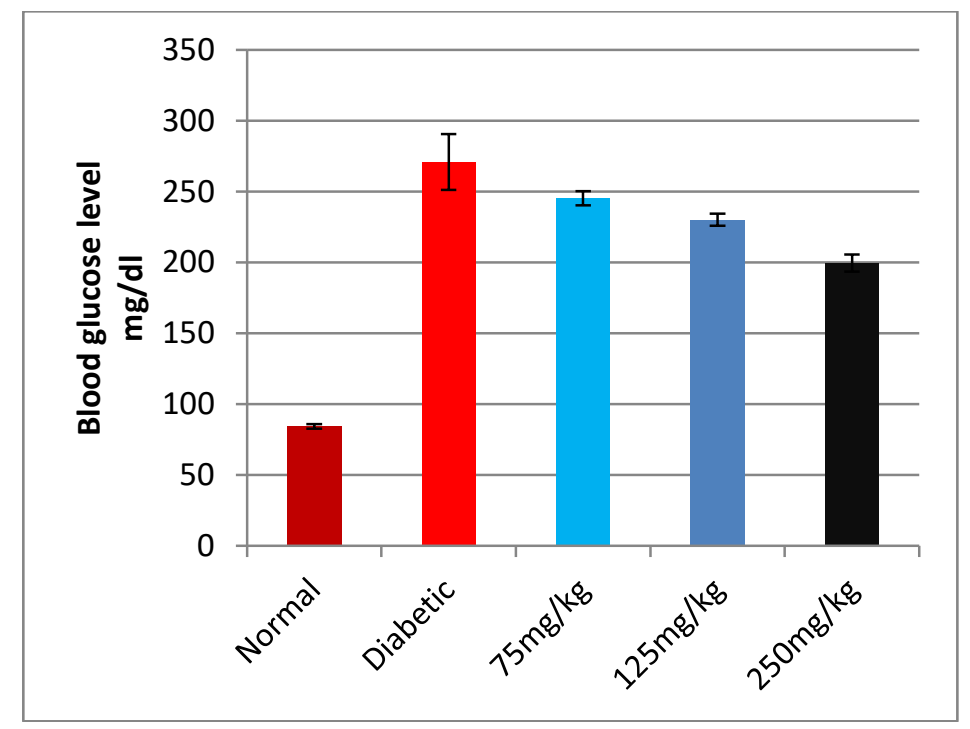

Fig - 2 Effect of CSBMEt on STZ induced diabetic rats

\section{DISCUSSION}

The importance of plants is known to us well. The plant kingdom is a treasure house of potential drugs and in the recent years there has been an increasing awareness about the importance of medicinal plants. Drugs from the plants are easily available, less expensive, safe, and efficient and rarely have side effects. The plants which have been selected for medicinal use over thousands of years constitute the most obvious choice of examining the current search for therapeutically effective new drugs [17]. The importance of medicinal plants, and the contribution of phytomedicine to the well-being of a significant number of the world's population, has attracted interest from a variety of disciplines [18]. It is concerned with enormous variety or organic substances namely alkaloids, carotenoids, steroids, flavonoids, terpenoid, etc. are elaborated and accumulated by plants and deals with the chemical structures of these substances the biosynthesis turn and metabolism natural distribution and their biological function [19].

Diabetes mellitus is a metabolic disease characterized by high blood glucose levels due to absolute or relative deficiency of circulatory insulin levels [20]. Currently available therapy for diabetes includes insulin and various oral hypoglycemic agents such as Sulphonylureas, metformin, glycosidase inhibitors, troglitazone, etc. But these are reported to produce serious adverse side effects such as liver problems, lactic acidosis and diarrhea [21]. Therefore, the search for more safer, specific, and effective hypoglycemic agents has continued to be an important area of investigation with natural extracts from readily available traditional medicinal plants offering great potential for discovery of new antidiabetic drugs [22,23]. We have already reported that Chloroxylon swietenia bark extracts possess the presence of flavonoids, tannins, glycosides and phenols in both methanol and aqueous extract [24].

Toxicity is an expression of being poisonous, indicating the state of adverse effects led by the interaction between toxicants and cells. This interaction may vary depending on the chemical properties of the toxicants and the cell membrane, as it may occur on the cell surface, within the cell body, or in the tissues beneath as well as at the extracellular matrix. The toxic effects may take place prior to the binding of the toxicants to the vital organs such as liver and kidneys. Hence, evaluation of toxic properties of a substance is crucial when considering for public health protection because exposure to chemicals can be hazardous and results to adverse effects on human being. In practice, the evaluation typically includes acute, sub-chronic, chronic, carcinogenic and reproductive effects [25]. A toxic substance might elicit interesting pharmacological effects at a lower non-toxic dose. Toxicity results from animals will be crucial in definitively judging the safety of medicinal plants if they are found to have sufficient potential for development into 
pharmacological products. Acute toxicity is mainly to obtain an appropriate dose for long-term toxicity tests [26].

Previous researcher have investigated the lipid profile and ocular antioxidant potential of Chloroxylon swietenia whole plant extracts on STZ-nicotinamide induced diabetic rats, it suggest that Chloroxylon swietenia whole plant extracts has the ability to control diabetes by lowering the blood sugar level at 250 and $500 \mathrm{mg} / \mathrm{kg} \mathrm{b.w}$. of the animal [11]. Acute toxicity studies with $P$. americana fruit extract were performed in experimental rats. Graded doses of ethanol extract of avocado fruits $(100,250,500$, and $1000 \mathrm{mg} / \mathrm{kg}$ body weight) no lethality was observed and dosage fixation studies $(100,200,300,400$ and $500 \mathrm{mg} / \mathrm{kg}$ body weight), into STZ-induced hyperglycaemia; it was found that the fruit extract shows its maximal hypoglycemic effect at the concentration of $300 \mathrm{mg} / \mathrm{kg}$ body [27]. Same results were observed by Gurudeeban et al., (2015) [28]. Our present findings on acute toxicity and dose fixation study are in agreement with the previous findings.

\section{CONCLUSION}

The present study confirms thus, the extracts of Chloroxylon swietenia bark (CSBMEt and CSBAEt) does not produce any toxic symptoms or death up to $1000 \mathrm{mg} / \mathrm{kg}$. Oral administration of $250 \mathrm{mg} / \mathrm{kg}$ of CSBMEt and CSBAEt lowered the blood sugar levels of STZ induced diabetic rats. With these results it can be concluded that $250 \mathrm{mg} / \mathrm{kg}$ of CSBMEt and CSBAEt can effectively used for the further studies.

\section{Acknowledgement}

One of the author B. Jayaprasad (IF120300) wishes to thank DST INSPIRE Fellowship Govt. of India, New Delhi, for providing financial support to carry out this research.

\section{References}

[1] Bastaki. S, Diabetes mellitus and its treatment. International Journal of Diabetes and Metabolism, 1995;13;111-134.

[2] Adeghate. E, Schatter. P, Dunn. E. An update on the etiology and epidemiology of diabetes mellitus. Ann NY Acad Sci, 2006:1084:1-29.

[3] Wild. S, Roglie. G, Green. A, King. H. Global prevalence of diabetes: estimates for the year 2000 and projections for 2030. Diabetes Care, 2004;27:1047-105.

[4] Wu. C, Li. Y, Chen . Y et al., Hypoglycemic effect of Belamcanda chinensis leaf extract in normal and STZ-induced diabetic rats and its potential active faction, Phytomedicine, 2011;18(4):292-297.

[5] Tiwari. AK, Madhusudana. RJ. Diabetes mellitus and multiple therapeutic approaches of phytochemicals: present status and future prospects. Current Science, 2002;83:30-8.

[6] American Diabetes Association. Diagnosis and classification of diabetes mellitus. Diabetes Care, 2005:28:37-42.

[7] Venkateshwarlu. E, Sharvanabhava. BS, Arvind. P, Rakeshkumar. Reddy. P, Dileep. P, Mahathi. K. Evaluation of anti-diabetic and hypolipidemic activity of Pseudarthria viscida (whole plant) in streptozotocin-nicotinamide induced Type II diabetic rats. Glob J Pharmacol 2013;7:192-7.

[8] Hansotia. T, Drucker. DJ. GIP and GLP-1 as incretin hormones: lessons from single and double incretin receptor knockout mice. Regulatory Peptides 2005;128:125-134. 
[9] Liu. JP, Zhang, M, Wang, WY, Grimsgaard, S. Chinese herbal medicines for type-2 diabetes mellitus. Cochrane Database of Systematic Reviews, 2004;3:3642.

[10] Cragg. GM, Newman. DJ. Natural product drug discovery in the next millennium. Pharm. Biol, 2001;39(1):8-17.

[11] Patchimatla. A, Kankanala. SR, Bandaru. SS, Kulindaivelu. U, Jupally. VR, Eggadi. V. Investigation of lipid profile and ocular oxidative stress of Chloroxylon swietenia on Streptozotocin-nicotinamide induced diabetic rats. Int J Green Pharm 2014;8:90-6.

[12] Jayaprasad. B, Sharavanan. PS, Karthik K. Chloroxylon swietenia an IUCN red listed plant medicinal uses. Int J Res Eng Biosci, 2014;2:213-217.

[13]. Ghosh, MN. Toxicity studies. In: Fundamentals of Experimental Pharmacology. Scientific Book Agency, Calcutta, 1984;153-158.

[14]. Turner. MA. 1965. Screening Methods in Pharmacology. Academic Press, New York, p. 26.

[15]. Gupta. R, Gupta. RS. Hypolipidemic activity of Pterocarpus marsupium in streptozotocin induced diabetes. J Complementary Integrative Med. 2009; 6: 1-28.

[16]. Kumar. V, Yadav. PKS, Singh. UP, Bhat. HR, Zaman. K, Ali. MD: Isolation of new racemic sugar (D/L galacturonic acid) from leaves of Paederia foetida Linn. Nature Proc 2011. doi:10.1038/npre.2011.5752.1.

[17]. Dewick, PM. 1996. Tumor inhibition from plants: Tease and Evans.

[18]. Prosper-Cabral. N. Biapa, Gabriel A. Agbor, Julius E. Oben, Jeanne Y. Ngogang. Phytochemical studies and antioxidant properties of four medicinal plants used in Cameroon. Afr. J. Trad. Cam. 2007:4(4); 495 - 500.

[19]. Harborne. JB, Phytochemicals methods, A guide to modern techniques of plant analysis, Chapman and hall London 1973.

[21]. Venkatesh. S, Reddy. GD, Reddy. BM, Ramesh. M, Apparao. AVN. Fitoterapia, 2003, 74, 274-279.

[22]. Rajalakshmi. M, Eliza. J, Priya. CE, Nirmala. A, Daisy. P. Afr.J.Pharm.Pharmacol., 2009, 3, $5,171-180$.

[23]. Patwardhan. B, Vaidya. ADB, Chorghade M, 2004. Ayurveda and natural products drug discovery. Current sciences, 86(6): 789-799.

[24]. Jayaprasad. B, Sharavanan. PS. Phytochemical, In Vitro Antioxidant and Antimicrobial Activities in Aqueous and Methanol Extracts Of Chloroxylon Swietenia Bark. RJPBCS 2015:6(1);1416-1424.

[25]. Asante-Duah, K. Public Health Risk Assessment for Human Exposure to Chemicals (illustrated.); Kluwer Academic Publishers: Dordrecht, The Netherlands, 2002; Volume 6.

[26]. Moshi, MJ. Brine shrimp toxicity evaluation of some Tanzanian plants used traditionally for the treatment of fungal infections. Afr. J. Tradit. Complement. Altern. Med. 2007, 4, 219-225.

[27]. Mahadeva Rao US, Bizuneh Adinew. Remnant $\beta$-cell-stimulative and anti-oxidative effects of persea americana fruit extract studied in rats introduced into streptozotocin - induced hyperglycaemic state. Afr J Tradit Complement Altern Med. (2011) 8(3): 210-217.

[28]. Gurudeeban. S, Satyavani. K, Sengottuvel. S, Thamotharan. G, Ramanathan. T. Antidiabetic and Antihyperlipidemic Effects of Rhizophora apiculata Blume Extracts. The Pharma Innovation Journal 2015; 4(6): 31-35. 